\title{
Physiological analysis of simple rapid movements in patients with cerebellar deficits
}

\author{
Mark Hallett, Alfredo Berardelli, Jean Matheson, John Rothwell, C D Marsden
}

\begin{abstract}
Patients with cerebellar deficits made elbow flexion movements as rapidly as possible for three different angular distances. Electromyographic activity of biceps and triceps and the kinematics of the movements were analysed. Results were compared with those of normal subjects making both rapid and slow movements. In the patients, the first agonist burst of the biceps was frequently prolonged regardless of the distance or speed of the movement. The most striking kinematic abnormality was prolonged acceleration time. The pattern of acceleration time exceeding deceleration time was common in patients but uncommon in normal subjects. The best kinematic correlate of the duration of the first agonist burst was acceleration time. Altered production of appropriate acceleration may therefore be an important abnormality in cerebellar dysfunction for attempted rapid voluntary movements.
\end{abstract}

Although it is clear that the cerebellum contributes to the coordination of voluntary movement, the nature of the contribution is not well understood. One prevalent idea is that the cerebellum acts like a clock to control the timing of movement. ${ }^{1-4}$ The analysis of simple rapid, or ballistic, movements appears to be a good approach to probe the timing of movement. Such movements are accomplished in normal persons in a stereotypical fashion with predictable timing. ${ }^{5-7}$ The pattern, sometimes called the "triphasic pattern," is characterised on the electromyogram (EMG) by an initial burst of muscle activity in the agonist of the movement that lasts $50-100 \mathrm{~ms}$. The agonist then falls silent and the antagonist muscle produces a burst that also lasts for $50-100 \mathrm{~ms}$. Then the agonist again resumes activity, often in the form of a burst. For angular movements of less than 30 or 40 degrees, the timing of the movement changes only a little; larger movements are accomplished with higher velocities. For movements of larger amplitude, the duration of the movement may increase and the EMG bursts would be prolonged. ${ }^{8-9}$ Slow movements are characterised by long EMG bursts that parallel the duration of the movement. $^{5}$

A previous study ${ }^{10}$ of attempted ballistic movements in patients with cerebellar deficits showed the triphasic pattern of EMG activity, but the duration of the first agonist burst was prolonged. The relationship between the EMG features and the kinematics of the movements was not analysed, but it was speculated that this prolonged burst might predispose the patients to hypermetric movements. The prolonged activity in the agonist muscle would move the limb for a longer time than was expected. This study examines the kinematic consequences of the prolonged EMG activity. Early in the investigation, we found that patients with cerebellar deficits often make movements that are either hypermetric or slower than normal, or both. Both large amplitude movements and slow movements in normal subject are characterised by prolongation of the first agonist EMG burst. Therefore we found it necessary to reconsider the question of whether patients with cerebellar deficits actually produce long first agonist bursts.

\section{Patients and methods}

We studied 13 patients, nine men and four women, aged 16 to 80 years, with cerebellar deficits in the arm, but no other neurological signs. Cerebellar signs in the arm were dysmetria, dysdiadochokinesia, and excessive rebound. Tremor was not prominent in any patient. Patients such as these are not common, as most who have clinical cerebellar signs also have corticospinal tract signs, sensory disturbance, weakness, or peripheral neuropathy. The dominant arm was studied unless the cerebellar deficit was restricted to or significantly worse in the nondominant arm. The patients had a variety of aetiological diagnoses (table 1). Sixteen normal subjects, all men, aged 20 to 75 years, were also studied. All but one of these subjects was right handed, and the dominant arm was studied.

Patients and normal subjects were asked to make flexion movements of their elbows as rapidly as possible. They sat in a chair facing an oscilloscope screen with their arms strapped into a lightweight splint composed of an upper arm and forearm portion connected at the level of the elbow joint with a low-friction hinge. In the hinge was a potentiometer that allowed measurement of the elbow angle by a voltage. The beam on the oscilloscope screen was made into a line, the height of which indicated the elbow angle. Subjects were asked to make movements of 10,20 , and 30 degrees by specifying the beginning and end- 
Table 1 Clinical description of patients with cerebellar deficits

\begin{tabular}{|c|c|c|c|c|}
\hline Patient & Age/sex & Diagnosis & $\begin{array}{l}\text { Degree of } \\
\text { ataxia }\end{array}$ & $\begin{array}{l}\text { Handed/ } \\
\text { hand studied }\end{array}$ \\
\hline $\begin{array}{r}1 \\
2 \\
3 \\
4 \\
5 \\
6 \\
7 \\
8 \\
9 \\
10 \\
11 \\
12 \\
13\end{array}$ & $\begin{array}{l}80 / \mathrm{F} \\
68 / \mathrm{M} \\
21 / \mathrm{M} \\
38 / \mathrm{M} \\
60 / \mathrm{M} \\
40 / \mathrm{F} \\
55 / \mathrm{F} \\
58 / \mathrm{M} \\
30 / \mathrm{M} \\
43 / \mathrm{M} \\
35 / \mathrm{M} \\
16 / \mathrm{M} \\
40 / \mathrm{F}\end{array}$ & $\begin{array}{l}\text { Familial cerebellar atrophy; severe cerebellar atrophy on CT scan } \\
\text { Carcinomatous cerebellar degeneration; CT scan normal } \\
\text { S/P surgical excision of astrocytoma of cerebellum } \\
\text { OPCA; cerebellar and pontine atrophy on CT scan } \\
\text { OPCA; small pons, medulla, and cerebellum on CT scan } \\
\text { Cerebellar degeneration; cerebellar atrophy on CT scan } \\
\text { OPCA; cerebellar atrophy on CT scan } \\
\text { Bilateral cerebellar infarctions } \\
\text { Multiple sclerosis } \\
\text { Multiple sclerosis; CT scan normal } \\
\text { Left cerebellar haemorrhage, demonstrated by CT scan } \\
\text { "Ramsay Hunt"; cerebellar atrophy on CT scan } \\
\text { Multiple sclerosis }\end{array}$ & $\begin{array}{l}\text { Severe } \\
\text { Severe } \\
\text { Severe } \\
\text { Severe } \\
\text { Severe } \\
\text { Moderate } \\
\text { Moderate } \\
\text { Moderate } \\
\text { Moderate } \\
\text { Mild } \\
\text { Mild } \\
\text { Mild } \\
\text { Mild }\end{array}$ & $\begin{array}{l}\mathbf{R} / \mathbf{R} \\
\mathbf{R} / \mathbf{R} \\
\mathbf{R} / \mathbf{R} \\
\mathbf{R} / \mathbf{R} \\
\mathbf{R} / \mathbf{R} \\
\mathbf{R} / \mathbf{R} \\
\mathbf{R} / \mathbf{R} \\
\mathbf{R} / \mathbf{R} \\
\mathbf{R} / \mathbf{R} \\
\mathbf{R} / \mathbf{R} \\
\mathbf{R} / \mathbf{L} \\
\mathbf{R} / \mathbf{L} \\
\mathbf{L} / \mathbf{R}\end{array}$ \\
\hline
\end{tabular}

OPCA = olivopontocerebellar atrophy.

ing heights of the line. The command to initiate movement was a verbal request to make the movement itself as rapidly as possible. Subjects were told that accuracy was less important than speed. The EMG was recorded with pairs of surface electrodes placed longitudinally over the bellies of the biceps brachii and triceps brachii. Subjects performed some practice trials until they were comfortable, and then data from a minimum of ten single consecutive trials were collected for each movement distance. The agonist and antagonist EMG and the elbow position voltage were recorded by computer. Most normal subjects were also asked to make a set of ten movements at each distance with variable slow speeds. Five normal subjects were also asked to make a set of ten movements of 60 degrees, both rapidly and more slowly.

We analysed the EMG for the duration and "amount" of activity within bursts. The beginning of the first agonist burst was the onset of EMG activity. The end of the first agonist burst was determined on the basis of two criteria applied in order. According to the first criterion, the end was indicated by any substantial decline in the amplitude of agonist EMG activity relating to the pause between the two agonist bursts. The pause was often accompanied by the peak of activity in the antagonist muscle. We looked for the end of the first agonist burst from $20 \mathrm{~ms}$ before to $20 \mathrm{~ms}$ after the start of the first antagonist burst, which could be recognised not only by initiation of activity but also by restart of activity after a pause or a sudden increase in activity. The second criterion specified that there should be a simultaneous decrease in the magnitude of the EMG to less than $10 \%$ of peak magnitude lasting for more than $10 \mathrm{~ms}$. It was expected that this decrease would occur before the peak velocity of the movement (the peak velocity was defined as the highest velocity at or before the time the acceleration first went to zero). If there was no end to the first agonist activity before $50 \mathrm{~ms}$ after the
Figure 1 Individual elbow flexion movements from a normal subject moving as fast as possible. The four traces in each panel are, from top to bottom, rectified biceps EMG, rectified triceps EMG, angular position, and velocity. The line under the EMG of the biceps record indicates the

measurement of the first agonist burst duration in that record. A shows a nicely formed triphasic pattern. B-D show co-contraction of the antagonist during the first agonist burst. In $B$, it is not clear whether the antagonist activity is only the first antagonist burst with an early start or whether there is some co-contraction activity also. In $C$, there is a clear separation of the first agonist burst and co-contraction activity; in $D$, the separation is not clear.

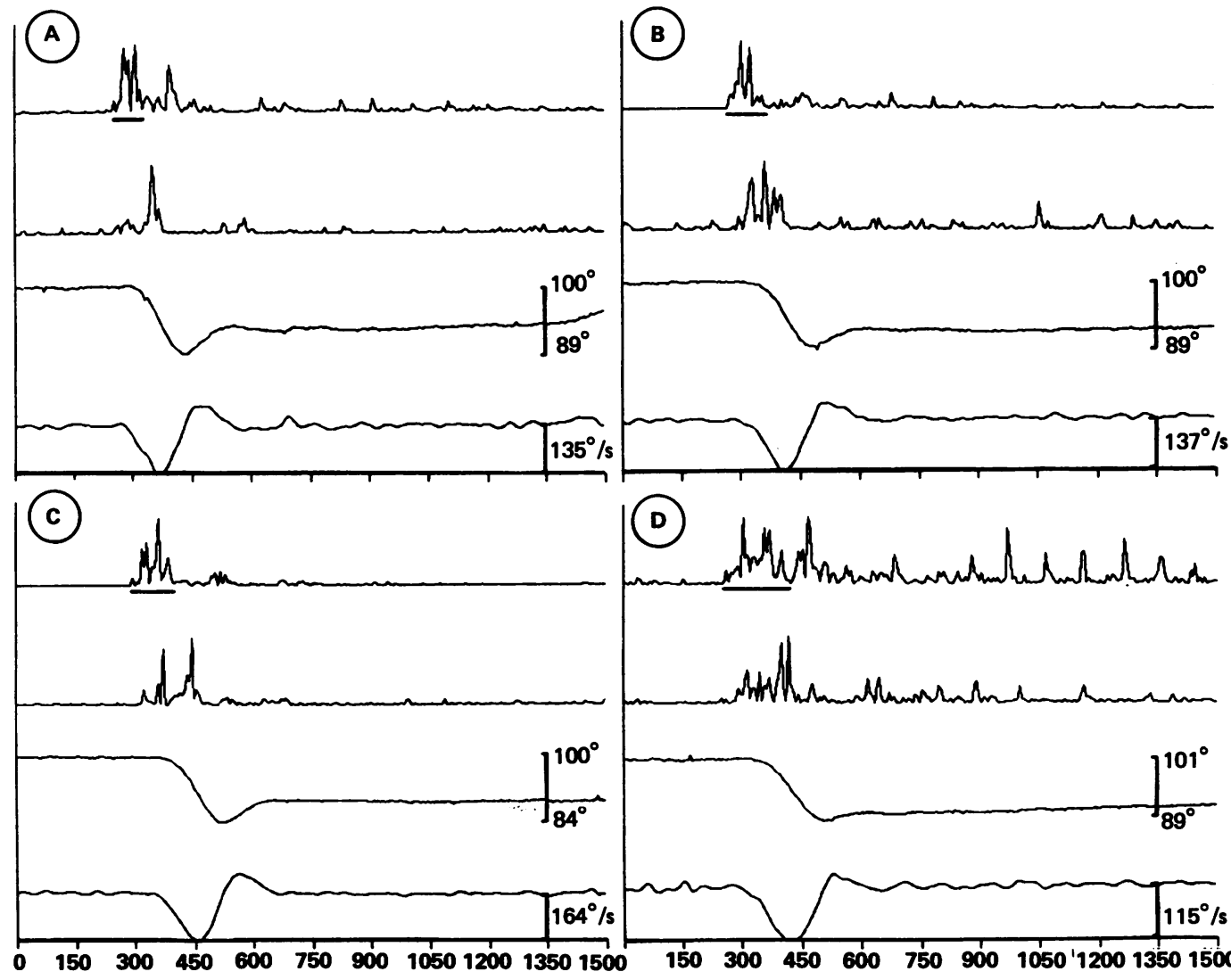


Figure 2 Individual elbow flexion movements from normal subjects moving slowly. The four traces in each panel are in the same order as in fig 1. The line under the EMG of the biceps record indicates the measurement of the first agonist burst duration in that record. Note the prolongation of the first agonist burst compared with the records in fig 1 and the fragmentation of some of the bursts. $B$ shows co-contraction activity of the agonist with the latter part of the first antagonist burst.

Figure 3 Individual elbow flexion movements from three patients moving as fast as possible ( $A$ and $D$, patient $9 ; B$, patient $3 ; C$, patient 5 ). The four traces in each panel are in the same order as in fig 1. The line under the EMG of the biceps record indicates the measurement of the first agonist burst duration in that record. The first agonist burst is mildly prolonged in $A$ and markedly prolonged in $B$ and $C$. In $C$, the first agonist burst is fragmented. $D$ shows the relatively rare event of tremorous movement.
(A)

(B)

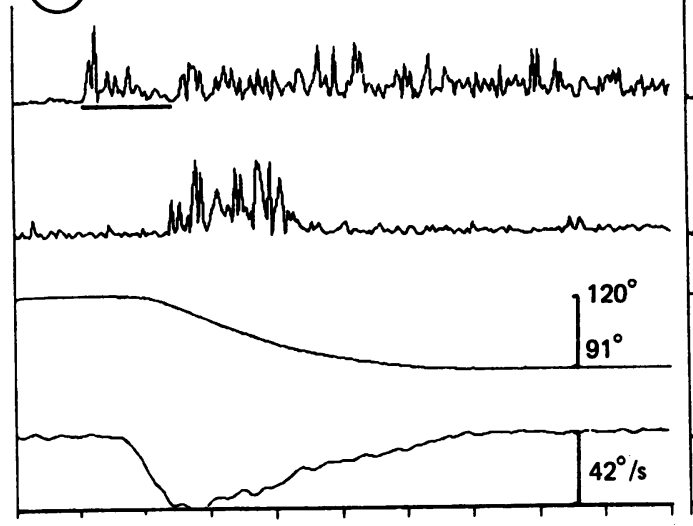

(c)

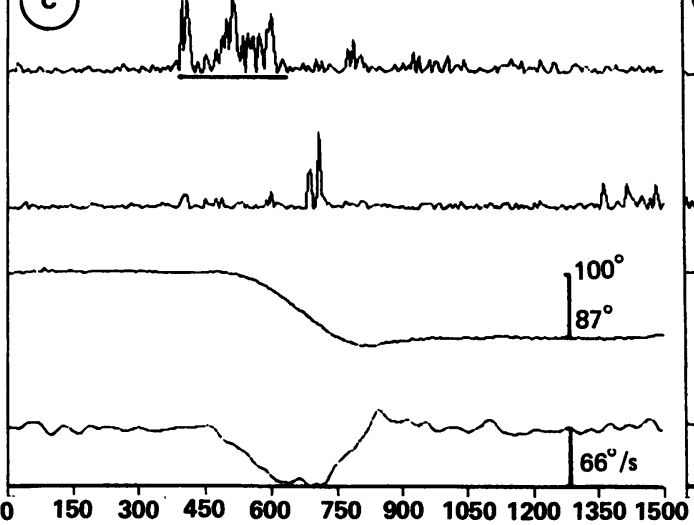

(D)

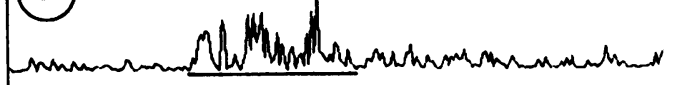

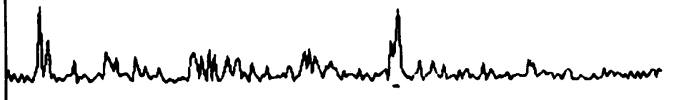
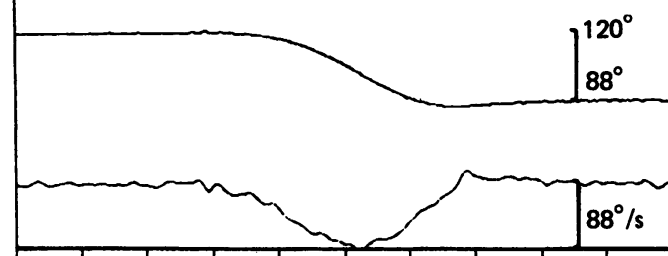

(A)

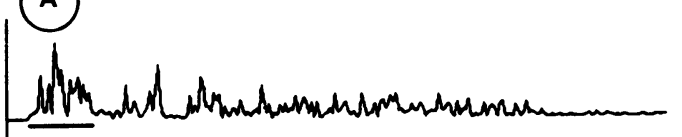

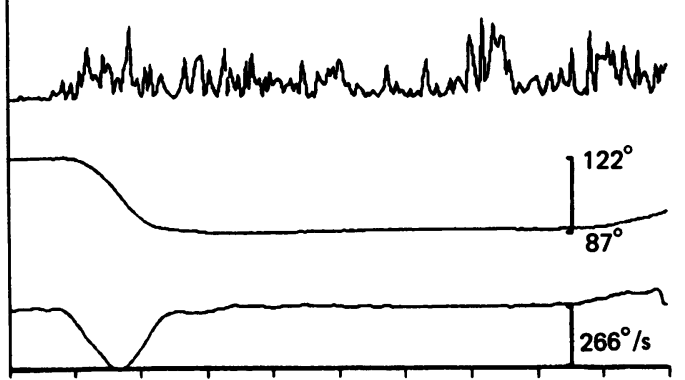

(c)

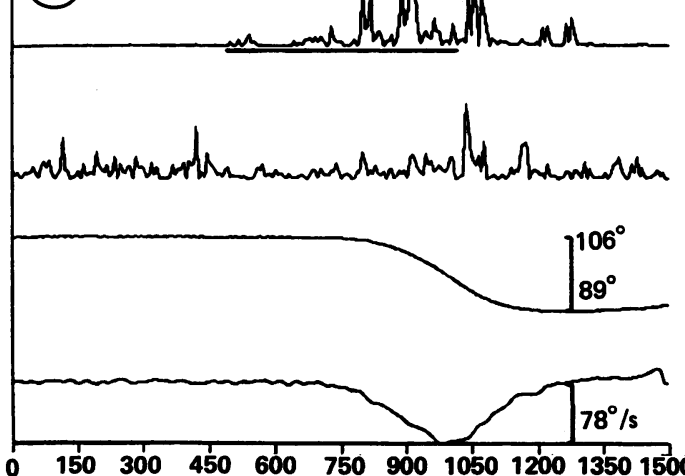

(B)
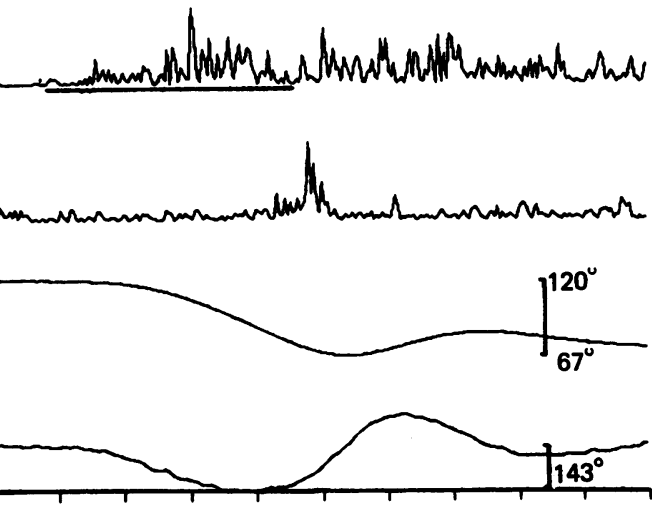

(D)

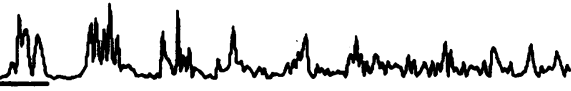

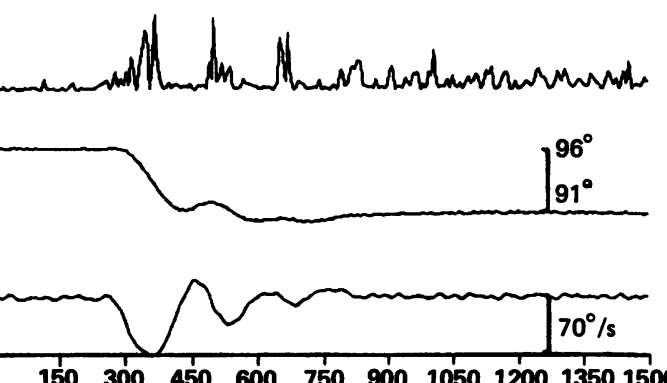


Table 2 Duration of first agonist burst ( $m s$ ) and coefficient of variation (CV)

\begin{tabular}{|c|c|c|c|c|c|c|c|c|c|}
\hline \multirow[b]{2}{*}{ Subject } & \multicolumn{3}{|l|}{$10^{\circ}$} & \multicolumn{3}{|l|}{$20^{\circ}$} & \multicolumn{3}{|l|}{$30^{\circ}$} \\
\hline & Mean & $C V$ & $N^{a}$ & Mean & $C V$ & $N^{a}$ & Mean & $C V$ & $N^{a}$ \\
\hline \multicolumn{10}{|c|}{ Normal subjects ${ }^{b}$} \\
\hline $\begin{array}{l}\text { N1 } \\
\text { N2 } \\
\text { N3 } \\
\text { N5 } \\
\text { N6 } \\
\text { N7 } \\
\text { N8 } \\
\text { N9 } \\
\text { N10 } \\
\text { N11 } \\
\text { N12 } \\
\text { N13 } \\
\text { N14 } \\
\text { N15 } \\
\text { N16 }\end{array}$ & $\begin{array}{r}70 \cdot 0 \\
90.0 \\
88.0 \\
78.9 \\
75.0 \\
117.0 \\
94.0 \\
70.0 \\
70.0 \\
66.3 \\
72.5 \\
72.5 \\
82.0 \\
86.4 \\
84.7\end{array}$ & $\begin{array}{l}32 \cdot 9 \\
22 \cdot 9 \\
22 \cdot 9 \\
38 \cdot 0 \\
14 \cdot 7 \\
17 \cdot 7 \\
27 \cdot 1 \\
24 \cdot 3 \\
10 \cdot 6 \\
16 \cdot 9 \\
27 \cdot 6 \\
21 \cdot 4 \\
14 \cdot 9 \\
14 \cdot 7 \\
12 \cdot 1\end{array}$ & & $\begin{array}{r}135.0 \\
94.5 \\
91.8 \\
89.0 \\
77.0 \\
117.0 \\
106.0 \\
86.3 \\
72.5 \\
65.0 \\
88.8 \\
81.3 \\
93.2 \\
90.4 \\
97.2\end{array}$ & $\begin{array}{r}12.2 \\
18.0 \\
26.9 \\
43.8 \\
10.4 \\
16.2 \\
23.2 \\
12.3 \\
16.6 \\
24.6 \\
7.3 \\
13.5 \\
19.3 \\
10.5 \\
10.8\end{array}$ & & $\begin{array}{r}130.0 \\
93.6 \\
115.0 \\
115.0 \\
75.0 \\
118.0 \\
113.0 \\
92.5 \\
83.8 \\
88.8 \\
92.5 \\
81.3 \\
85.6 \\
103.2 \\
101.6\end{array}$ & $\begin{array}{r}19 \cdot 2 \\
10 \cdot 6 \\
28 \cdot 0 \\
9 \cdot 1 \\
18 \cdot 0 \\
19 \cdot 5 \\
20.5 \\
11 \cdot 6 \\
9 \cdot 0 \\
10 \cdot 1 \\
17 \cdot 3 \\
12 \cdot 7 \\
17 \cdot 1 \\
14.4 \\
14.5\end{array}$ & \\
\hline $\begin{array}{l}\text { Mean } \\
\text { SD }\end{array}$ & $\begin{array}{l}81 \cdot 2 \\
13 \cdot 1\end{array}$ & $\begin{array}{r}21 \cdot 2 \\
7 \cdot 8\end{array}$ & & $\begin{array}{l}92 \cdot 3 \\
17 \cdot 3\end{array}$ & $\begin{array}{r}17 \cdot 7 \\
9 \cdot 2\end{array}$ & & $\begin{array}{l}99 \cdot 3 \\
16 \cdot 0\end{array}$ & $\begin{array}{r}15 \cdot 4 \\
5 \cdot 2\end{array}$ & \\
\hline $\begin{array}{r}1 \\
2 \\
3 \\
4 \\
5 \\
6 \\
7 \\
9 \\
10 \\
11 \\
12 \\
13\end{array}$ & $\begin{array}{l}235 \cdot 0^{\star} \\
166 \cdot 7^{\star} \\
\text { ND } \\
\text { ND } \\
380 \cdot 0^{\star} \\
188 \cdot 4^{\star} \\
210 \cdot 0^{\star} \\
100 \cdot 0 \\
116 \cdot 3^{\star} \\
97 \cdot 5 \\
89 \cdot 2 \\
101 \cdot 6\end{array}$ & $\begin{array}{l}34 \cdot 2 \\
35 \cdot 3 \\
\\
31 \cdot 0 \\
10 \cdot 3 \\
33 \cdot 8 \\
21 \cdot 2 \\
24 \cdot 0\end{array}$ & $\begin{array}{c}10 / 10 \\
10 / 10 \\
2 / 11 \\
10 / 10 \\
8 / 8 \\
4 / 4 \\
10 / 10 \\
10 / 10\end{array}$ & $\begin{array}{l}218 \cdot 9^{\star} \\
218 \cdot 0^{\star} \\
\text { ND } \\
119 \cdot 0 \\
386 \cdot 0^{\star} \\
242 \cdot 0^{\star} \\
172 \cdot 5^{\star} \\
119 \cdot 0 \\
125 \cdot 0 \\
156 \cdot 7^{\star} \\
105 \cdot 6 \\
129 \cdot 2\end{array}$ & $\begin{array}{c}\text { ients }^{c} \\
68 \cdot 5^{\star} \\
31 \cdot 7 \\
16 \cdot 8 \\
34 \cdot 2 \\
30 \cdot 1 \\
30 \cdot 3 \\
16 \cdot 0 \\
10 \cdot 4 \\
42 \cdot 1^{\star} \\
26 \cdot 2 \\
28 \cdot 2\end{array}$ & $\begin{array}{c}9 / 11 \\
5 / 5 \\
\\
10 / 10 \\
10 / 10 \\
10 / 10 \\
4 / 4 \\
10 / 10 \\
8 / 8 \\
9 / 10 \\
10 / 10 \\
10 / 10\end{array}$ & $\begin{array}{l}165 \cdot 7^{\star} \\
252 \cdot 5^{\star} \\
461 \cdot 1^{\star} \\
\text { ND } \\
262 \cdot 0^{\star} \\
273 \cdot 6^{\star} \\
170 \cdot 0^{\star} \\
136 \cdot 0 \\
123 \cdot 7 \\
129 \cdot 0 \\
139 \cdot 6^{\star} \\
151 \cdot 6^{\star}\end{array}$ & $\begin{array}{c}64 \cdot 0^{\star} \\
8 \cdot 7 \\
13 \cdot 8 \\
38 \cdot 2^{\star} \\
29 \cdot 5^{\star} \\
41 \cdot 8^{\star} \\
13 \cdot 2 \\
7 \cdot 3 \\
13 \cdot 2 \\
14 \cdot 0 \\
44 \cdot 1^{\star}\end{array}$ & $\begin{array}{c}7 / 11 \\
4 / 7 \\
9 / 10 \\
15 / 15 \\
10 / 10 \\
4 / 9 \\
10 / 10 \\
8 / 8 \\
10 / 10 \\
10 / 10 \\
10 / 10\end{array}$ \\
\hline $\begin{array}{l}\text { Mean } \\
\text { SD }\end{array}$ & $\begin{array}{r}168.5 \\
91.0\end{array}$ & $\begin{array}{r}27 \cdot 9 \\
8 \cdot 1\end{array}$ & & $\begin{array}{r}181 \cdot 1 \\
82 \cdot 7\end{array}$ & $\begin{array}{l}30.4 \\
15.6\end{array}$ & & $\begin{array}{l}205 \cdot 9 \\
101 \cdot 4\end{array}$ & $\begin{array}{l}26 \cdot 1 \\
18 \cdot 6\end{array}$ & \\
\hline
\end{tabular}

ND, not done.

Number of movements where EMG burst was measured/number of movements included in analysis (the kinematic measurements in tables 3 and 4 were taken from all movements included in analysis).

${ }^{b} \mathrm{EMG}$ artifact in subject $\mathrm{N} 4$ prohibited any measurement.

cPatient 8 showed only tonic EMG patterns.

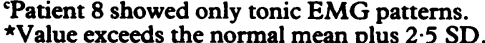

peak velocity, then the agonist burst was said to be "tonic" and not to have a measurable duration. The amount of activity was calculated by rectifying and continuously integrating the EMG record. The difference in value of the continuously integrated trace between the beginning and end of the burst gave the amount. We attempted a similar analysis for the first antagonist burst, but discontinued it because of considerable difficulties producing reliable data (see Results).

A patient value was considered abnormal if it deviated more than 2.5 standard deviations from the normal mean.

\section{Results}

\section{First antagonist burst}

Even for the normal subjects, it was not a simple matter to determine the duration of the first antagonist burst. The detail of the EMG pattern of the first antagonist burst was not constant, even for the same person attempting the same movement with similar kinematics (fig 1). Defining the start of the antagonist burst was difficult. The start was clearest when the burst began about the time that the first agonist burst stopped (fig 1A). "Co-contraction" of the antagonist with the agonist often occurred, and while it was usually possible to separate the co-contraction from the antagonist burst itself (fig 1C), it was difficult to decide whether the start of the antagonist contraction was a co-contraction or an early start of the burst (fig 1B). Many times, definite co-con- traction antagonist activity continued directly into the burst, making it impossible to define the burst onset (fig 1D). Defining the end of the antagonist burst was also a problem; the EMG activity did not clearly stop, but continued in a tonic fashion, sometimes with the appearance of co-contraction with the second agonist burst (figs $2 B$ and $3 A$ ).

Finally, we decided that we could not establish objective criteria that would produce consistent data, and hence we will not report on the duration of the first antagonist burst.

\section{First agonist burst}

The duration of the first agonist burst was also not easy to determine, but by establishing the criteria described above we were able to measure it with some objectivity. Again, in the normal subjects, the EMG pattern of the first agonist burst was not constant, even for the same person attempting the same movement with similar kinematics (fig 1), but it was less variable than that of the first antagonist burst. The onset of the first agonist burst was nearly always clear, since the background was quiet. However, the end of the first agonist burst was often difficult to determine for several reasons. More often than not, the agonist did not fall completely silent at the "end" of the first burst. The activity would sometimes reduce substantially but continue at a low tonic level, or it would stop very briefly and then resume. At times, it would appear that some of the agonist activity was co-contraction activity with the antagonist. The problem was even more dif- 
Figure 4 Threedimensional plots of duration of the first agonist burst as a function of distance moved and peak velocity. Data from normal subjects $(A)$ are plotted as small round points. Data from patients 5, 2, and 1 , respectively $(B-D)$, are plotted as large round points on the background of the normal data.
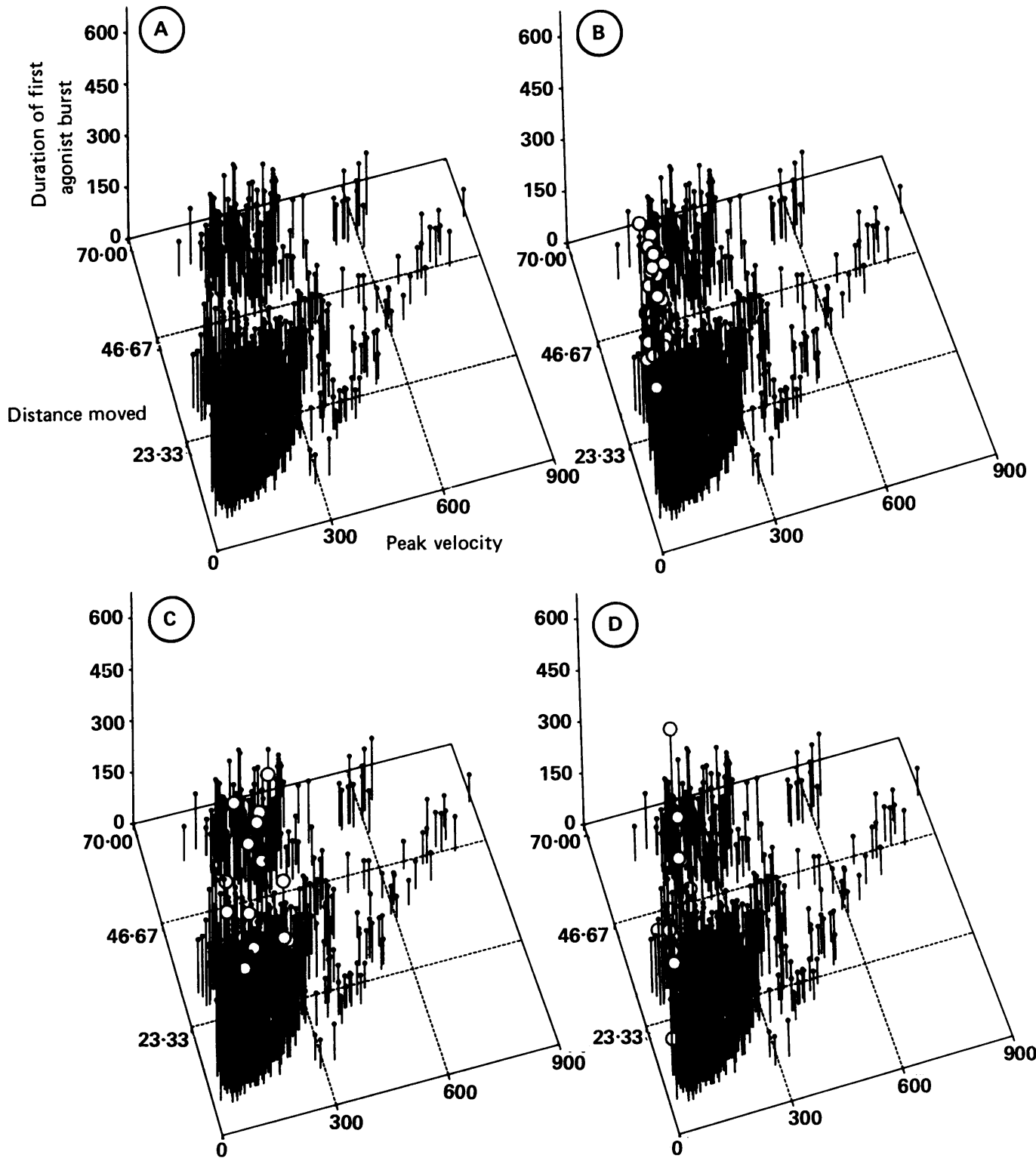

ficult with the normal slow movements (fig 2). Additionally, the first agonist burst fragmented, that is, there were substantial brief drops in EMG amplitude well before the first antagonist burst began or well before the peak velocity, or both (fig $2 \mathrm{C}, \mathrm{D}$ ).

These problems of measurement were even greater in the patients' records, with fragmentation of the first agonist burst being a common finding (fig 3C). Only rarely did patients have movements characterised by tremor, and it was not a significant problem when it occurred (fig 3D). Not infrequently, the first agonist burst in patients was underestimated because of the fragmentation and co-contraction problems.

The number of movements for which the bursts could be measured and the total number of acceptable movements (used for kinematic analyses) are shown in table 2 . Usually, all trials were measurable for the normal subjects, but in an occasional set of ten trials, one trial might not be measurable. In some patients, it was possible to measure all ten trials, but in many it was not. Some movements were performed so badly, including for example, movements in the wrong direction, that the trial was discar- ded. For some movements, the burst was not measurable because of a tonic or highly fragmented pattern.

Normal subjects making rapid movements of 10,20 , and 30 degrees had first agonist bursts averaging between 80 and $100 \mathrm{~ms}$ (table 2). Ten of 12 patients had first agonist bursts that were significantly longer than normal for at least one movement distance (one patient had long-duration agonist activity from which bursts could not be identified). Two-way analysis of variance (ANOVA) with burst duration as the dependent variable, and distance aimed and subject group as factors, showed a highly significant difference between the normal subjects and the patients $(p<0.001)$, but no difference with distance aimed and no significant interaction. Regression analysis showed no changes in the first agonist burst duration with age. A Kruskal-Wallis test showed that patients who had shorter bursts had milder ataxia than did those who had prolonged bursts ( $p<0.001$ ).

The duration of the first agonist burst was movements were slow or greater than 30 prolonged in normal subjects when the 
Table 3 Accuracy of movement (degrees) and coefficient of variation (CV)

\begin{tabular}{|c|c|c|c|c|c|c|}
\hline \multirow[b]{2}{*}{ Subject } & \multicolumn{2}{|l|}{$10^{\circ}$} & \multicolumn{2}{|l|}{$20^{\circ}$} & \multicolumn{2}{|l|}{$30^{\circ}$} \\
\hline & Mean & $C V$ & Mean & $C V$ & Mean & $C V$ \\
\hline \multicolumn{7}{|c|}{ Normal subjects } \\
\hline $\begin{array}{l}\text { N1 } \\
\text { N2 } \\
\text { N3 } \\
\text { N4 } \\
\text { N5 } \\
\text { N6 } \\
\text { N7 } \\
\text { N8 } \\
\text { N9 } \\
\text { N10 } \\
\text { N11 } \\
\text { N12 } \\
\text { N13 } \\
\text { N14 } \\
\text { N15 } \\
\text { N16 }\end{array}$ & $\begin{array}{r}12.8 \\
16.0 \\
12.4 \\
7.7 \\
11.6 \\
19.0 \\
12.1 \\
12.1 \\
9.9 \\
13.9 \\
12.1 \\
11.8 \\
10.6 \\
12.8 \\
12.0 \\
13.1\end{array}$ & $\begin{array}{r}13 \cdot 3 \\
38 \cdot 1 \\
21 \cdot 8 \\
9 \cdot 1 \\
25 \cdot 0 \\
8 \cdot 9 \\
37 \cdot 2 \\
17 \cdot 4 \\
11 \cdot 4 \\
14 \cdot 6 \\
19 \cdot 5 \\
18 \cdot 0 \\
12 \cdot 2 \\
17 \cdot 2 \\
24 \cdot 0 \\
12.5\end{array}$ & $\begin{array}{l}23 \cdot 3 \\
29 \cdot 6 \\
21 \cdot 7 \\
17 \cdot 4 \\
20 \cdot 3 \\
29 \cdot 3 \\
27 \cdot 2 \\
21 \cdot 7 \\
19.5 \\
19 \cdot 9 \\
21 \cdot 8 \\
19.9 \\
18 \cdot 8 \\
20.9 \\
20.4 \\
22.4\end{array}$ & $\begin{array}{r}14 \cdot 6 \\
17 \cdot 9 \\
17 \cdot 1 \\
14 \cdot 4 \\
16 \cdot 3 \\
19 \cdot 1 \\
6 \cdot 6 \\
4 \cdot 1 \\
12 \cdot 9 \\
15 \cdot 3 \\
12 \cdot 2 \\
12 \cdot 2 \\
7 \cdot 4 \\
16 \cdot 9 \\
16 \cdot 9 \\
13 \cdot 0\end{array}$ & $\begin{array}{l}30 \cdot 6 \\
47 \cdot 3 \\
33 \cdot 8 \\
29 \cdot 2 \\
30 \cdot 9 \\
38 \cdot 8 \\
40 \cdot 1 \\
31 \cdot 0 \\
29 \cdot 8 \\
31 \cdot 1 \\
28 \cdot 0 \\
29.9 \\
25 \cdot 1 \\
32 \cdot 8 \\
30.5 \\
31 \cdot 1\end{array}$ & $\begin{array}{r}9.2 \\
12.1 \\
9.8 \\
5.8 \\
8.7 \\
9.8 \\
5.5 \\
11.6 \\
5.9 \\
5.4 \\
12.1 \\
8.8 \\
8.6 \\
11.8 \\
8.9 \\
4.8\end{array}$ \\
\hline $\begin{array}{l}\text { Mean } \\
\text { SD }\end{array}$ & $\begin{array}{r}12.5 \\
2.5\end{array}$ & $\begin{array}{r}18 \cdot 8 \\
8 \cdot 8\end{array}$ & $\begin{array}{r}22.1 \\
3.6\end{array}$ & $\begin{array}{r}13 \cdot 5 \\
4 \cdot 3\end{array}$ & $\begin{array}{r}32.5 \\
5.4\end{array}$ & $\begin{array}{l}8 \cdot 7 \\
2.5\end{array}$ \\
\hline $\begin{array}{r}1 \\
2 \\
3 \\
4 \\
5 \\
6 \\
7 \\
8 \\
9 \\
10 \\
11 \\
12 \\
13\end{array}$ & $\begin{array}{c}6 \cdot 8 \\
26 \cdot 9^{\star} \\
\text { ND } \\
\text { ND } \\
17 \cdot 4 \\
16 \cdot 0 \\
19 \cdot 5^{\star} \\
14 \cdot 1 \\
7 \cdot 3 \\
14 \cdot 6 \\
10 \cdot 0 \\
15 \cdot 5 \\
17 \cdot 7\end{array}$ & $\begin{array}{l}20 \cdot 1 \\
23 \cdot 8 \\
68 \cdot 7^{\star} \\
18 \cdot 4 \\
34 \cdot 2 \\
13 \cdot 7 \\
29 \cdot 0 \\
25 \cdot 2 \\
28 \cdot 2\end{array}$ & $\begin{array}{c}\text { Patients } \\
27 \cdot 5 \\
38 \cdot 8^{\star} \\
\text { ND } \\
30 \cdot 7 \\
20 \cdot 8 \\
25 \cdot 1 \\
24 \cdot 7 \\
26 \cdot 8 \\
19 \cdot 8 \\
25 \cdot 0 \\
21 \cdot 0 \\
28 \cdot 2 \\
34 \cdot 8^{\star}\end{array}$ & $\begin{array}{l}41 \cdot 8^{\star} \\
24 \cdot 0 \\
18 \cdot 2 \\
10 \cdot 1 \\
16 \cdot 3 \\
30 \cdot 0^{\star} \\
27 \cdot 2 \\
14 \cdot 6 \\
8 \cdot 8 \\
9 \cdot 5 \\
22 \cdot 7 \\
10 \cdot 6\end{array}$ & $\begin{array}{l}33 \cdot 3 \\
36 \cdot 6 \\
53 \cdot 8^{\star} \\
\text { ND } \\
32 \cdot 3 \\
37 \cdot 8 \\
42 \cdot 1 \\
42 \cdot 4 \\
32 \cdot 6 \\
32 \cdot 2 \\
31.5 \\
46 \cdot 2^{\star} \\
36 \cdot 2\end{array}$ & $\begin{array}{c}22 \cdot 8^{\star} \\
32 \cdot 5^{\star} \\
8 \cdot 9^{-} \\
6 \cdot 5 \\
16 \cdot 4^{\star} \\
17 \cdot 6^{\star} \\
11 \cdot 6^{\star} \\
19 \cdot 0^{\star} \\
10 \cdot 2^{2} \\
8 \cdot 6 \\
25 \cdot 1^{\star} \\
19 \cdot 6^{\star}\end{array}$ \\
\hline $\begin{array}{l}\text { Mean } \\
\text { SD }\end{array}$ & $\begin{array}{r}15 \cdot 1 \\
5 \cdot 7\end{array}$ & $\begin{array}{l}32 \cdot 2 \\
18 \cdot 3\end{array}$ & $\begin{array}{r}26.9 \\
5.7\end{array}$ & $\begin{array}{l}19 \cdot 5 \\
10 \cdot 1\end{array}$ & $\begin{array}{r}38.1 \\
6.9\end{array}$ & $\begin{array}{r}16 \cdot 6 \\
7 \cdot 8\end{array}$ \\
\hline
\end{tabular}

ND, not done.

^Value exceeds the normal mean plus 2.5 SD.

degrees. Accordingly, the burst durations in the patients might have been longer than normal because their movements were slow or hypermetric. From this point of view, it is essential to assess burst durations for movements matched for distance and velocity. To do this, we looked at the first agonist burst duration for individual movements as a simultaneous function of angular distance and peak velocity (fig 4). The three-dimensional plot of this relationship is a surface. The surface is flat and parallel to the plane of origin for rapid movements of less than 30 degrees. The edge of the surface, which comes from the most rapid movements that can be done for each distance, runs diagonally across the plane because longer movements can be accomplished at faster velocity. The surface moves upward with longer or slower movements. (The normal distribution surface has some "holes" that originate from not collecting data on any movements between 30 and 60 degrees and not collecting data on medium speed movements at 60 degrees.) In nine of 12 patients (all but patients 4,7 , and 11), at least some of the first agonist burst durations exceeded the normal distribution.

\section{Kinematics of the movements}

We defined the end point of the movement as the point at which the velocity first became zero. By this definition, normal subjects attempting to move rapidly made movements that were slightly hypermetric. The movement typically first overshot the desired endpoint and then quickly backtracked (fig 1). This type of trajectory was not present in normal subjects making slow movements (fig 2) or in any of the patients (fig 3), Even with this difference in trajectory, two-way ANOVA showed that the patients were more hypermetric than the normal subjects $(\mathrm{p}<0.001)$ (table 3$)$. The variability of the distance moved was assessed with the coefficient of variation of the distance moved for each distance aimed. Two-way ANOVA showed that the variability was greater in the patients than in the normal subjects ( $p<0.001$ ) and significantly different for the different movements (more variability with shorter movements).

It was apparent that many of the patients' movements were slow. We studied several parameters to characterise this deficit. The total movement time was the best measure, with eight of the 13 patients having at least one value statistically above normal. We divided the movement time into the acceleration time (beginning of the movement until the peak of the velocity) and the deceleration time (peak of the velocity until zero velocity). (If a corrective extension movement immediately followed the flexion movement, then the movement "decelerated" for some time longer than the deceleration time, but this additional time was not relevant to our end point.) The normal range of acceleration times was very tight, and nine of the 13 patients had abnormal acceleration times (table 4). Two-way ANOVA with acceleration time as the dependent variable, and distance aimed and subject group as factors, showed a highly significant difference between normal subjects and patients ( $p<0.001$ ), but no difference with distance aimed and no significant interaction. A Krusk-

Table 4 Acceleration time (ms)

\begin{tabular}{|c|c|c|c|}
\hline Subject & $10^{\circ}$ & $20^{\circ}$ & $30^{\circ}$ \\
\hline \multicolumn{4}{|c|}{ Normal subjects } \\
\hline $\begin{array}{l}\text { N1 } \\
\text { N2 } \\
\text { N3 } \\
\text { N5 } \\
\text { N6 } \\
\text { N7 } \\
\text { N9 } \\
\text { N10 } \\
\text { N11 } \\
\text { N12 } \\
\text { N13 } \\
\text { N14 } \\
\text { N15 } \\
\text { N16 }\end{array}$ & $\begin{array}{l}76 \cdot 0 \\
65 \cdot 6 \\
72 \cdot 5 \\
58 \cdot 0 \\
65 \cdot 0 \\
81 \cdot 0 \\
65 \cdot 0 \\
71 \cdot 3 \\
62 \cdot 5 \\
62 \cdot 5 \\
60 \cdot 0 \\
89 \cdot 2 \\
57 \cdot 2 \\
85 \cdot 8\end{array}$ & $\begin{array}{r}90 \cdot 0 \\
67.5 \\
77.5 \\
68 \cdot 5 \\
69 \cdot 0 \\
85.5 \\
77 \cdot 5 \\
86 \cdot 3 \\
82.5 \\
82.5 \\
80.0 \\
124.0 \\
68.8 \\
90.4\end{array}$ & $\begin{array}{r}105.0 \\
62.8 \\
81.5 \\
84.0 \\
79.5 \\
88.4 \\
101.3 \\
100.0 \\
93.8 \\
93.8 \\
87.5 \\
128.0 \\
84.4 \\
104.8\end{array}$ \\
\hline $\begin{array}{l}\text { Mean } \\
\text { SD }\end{array}$ & $\begin{array}{l}69 \cdot 4 \\
10 \cdot 3\end{array}$ & $\begin{array}{l}81 \cdot 8 \\
14.5\end{array}$ & $\begin{array}{l}91.8 \\
15.5\end{array}$ \\
\hline $\begin{array}{r}1 \\
2 \\
3 \\
4 \\
5 \\
6 \\
7 \\
8 \\
9 \\
10 \\
11 \\
12 \\
13\end{array}$ & $\begin{array}{l}441 \cdot 7^{\star} \\
137 \cdot 1^{\star} \\
\text { ND } \\
\text { ND } \\
250 \cdot 0^{\star} \\
129 \cdot 2^{\star} \\
155 \cdot 5^{\star} \\
284 \cdot 4^{\star} \\
95 \cdot 0 \\
80 \cdot 0 \\
80 \cdot 0 \\
131 \cdot 5^{\star} \\
136 \cdot 3^{\star}\end{array}$ & $\begin{array}{l}\text { ients } \\
256 \cdot 4^{\star} \\
132 \cdot 0^{\star} \\
\text { ND } \\
109 \cdot 0^{\star} \\
263 \cdot 0^{\star} \\
134 \cdot 7^{\star} \\
192 \cdot 5^{\star} \\
336 \cdot 2^{\star} \\
103 \cdot 0^{\circ} \\
88 \cdot 7 \\
83 \cdot 0^{\star} \\
171 \cdot 3^{\star} \\
170 \cdot 6^{\star}\end{array}$ & $\begin{array}{c}345 \cdot 5^{\star} \\
178 \cdot 6^{\star} \\
301 \cdot 0^{\star} \\
\text { ND } \\
270 \cdot 7^{\star} \\
167 \cdot 5^{\star} \\
185 \cdot 6^{\star} \\
407 \cdot 5^{\star} \\
121 \cdot 0^{\star} \\
88.7 \\
80.0 \\
182 \cdot 7^{\star}\end{array}$ \\
\hline $\begin{array}{l}\text { Mean } \\
\text { SD }\end{array}$ & $\begin{array}{l}174.6 \\
109.8\end{array}$ & $\begin{array}{r}170 \cdot 0 \\
79 \cdot 4\end{array}$ & $\begin{array}{l}209 \cdot 7 \\
101 \cdot 6\end{array}$ \\
\hline
\end{tabular}

ND, not done.

*Value exceeds the normal mean plus 2.5 SD. 
Figure 5 Threedimensional plots of acceleration time as a function of distance moved and peak velocity. Data from normal subjects $(A)$ and patients 5, 2, and 1 , respectively $(B-D)$, are plotted as in fig 4.
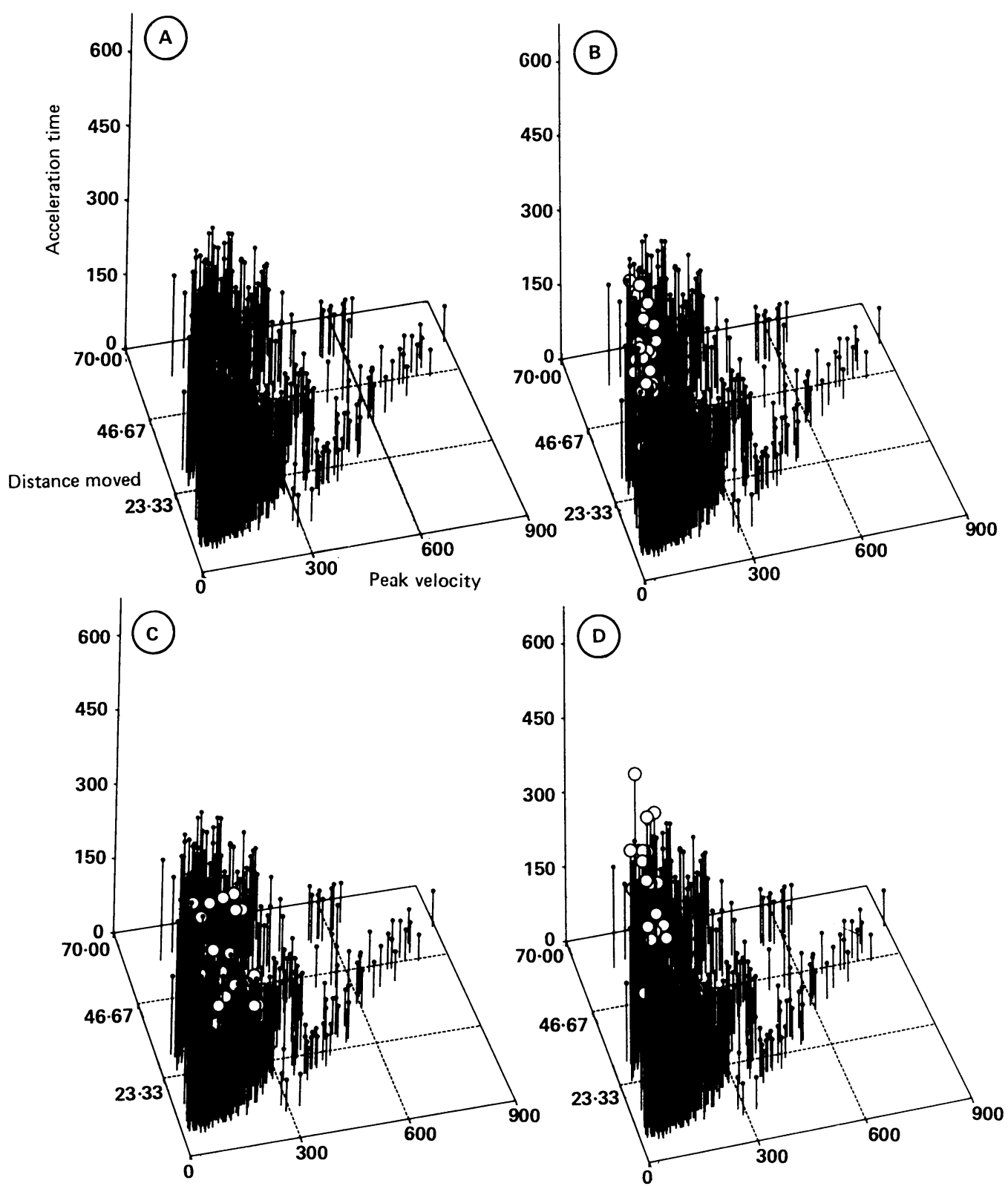

al-Wallis test showed that the severity of ataxia correlated with acceleration time $(\mathrm{p}=0.03)$. Many of the deceleration times were also abnormal, but not as dramatically; the values exceeded the normal range in nine patients.

Rapid movements of normal subjects yielded a symmetric velocity curve, the acceleration time being roughly equal to the deceleration time (fig 1). The attempted rapid movements of the patients, however, often showed a longer acceleration time than deceleration time (fig 3). Normal subjects making slow movements used a variety of strategies, but most commonly showed a longer deceleration time than acceleration time (fig 2A). To quantify these observations, we studied the ratio of acceleration time to deceleration time. The normal subjects had mean ratios of $0.94,0.99$, and 0.96 for the fast 10,20, and 30 degree movements, respectively. For the slow movements, the ratios dropped to $0 \cdot 88,0 \cdot 83$, and $0 \cdot 83$, respectively. The ratios for the patients were $1 \cdot 17$, $1 \cdot 09$, and $1 \cdot 08$, respectively. ANOVA showed no significant difference between the patients' movements and the normal fast movements, but there was a significant difference $(\mathrm{p}<0.05)$ when the patients' movements were compared with the normal slow movements.

For careful assessment of the apparent abnormalities of acceleration time and the ratio of acceleration time to deceleration time in the patients, it is necessary to look at individual movements. The acceleration time might well be expected to vary in different types of movements. With respect to the issues being considered here, we might expect the acceleration time (like the duration of the first agonist burst) to increase with distance moved and slowness of the movement. To explore this possibility, we studied acceleration times in individual movements as a simultaneous function of the distance moved and the peak velocity (fig 5). The three-dimensional plot of this relationship is a surface with a shape similar to that plotted for the duration of the first agonist burst, that is, flat and parallel to the plane of origin for fast movements of less than 30 degrees and rising for longer or slower movements. Ten patients showed long acceleration times with this type of plot, 
Figure 6 Threedimensional plots of the ratio of acceleration time to deceleration time as a function of distance moved and peak velocity. Data from normal subjects $(A)$ and patients 5, 2, and 1 , respectively $(B-D)$, are plotted as in fig 4.

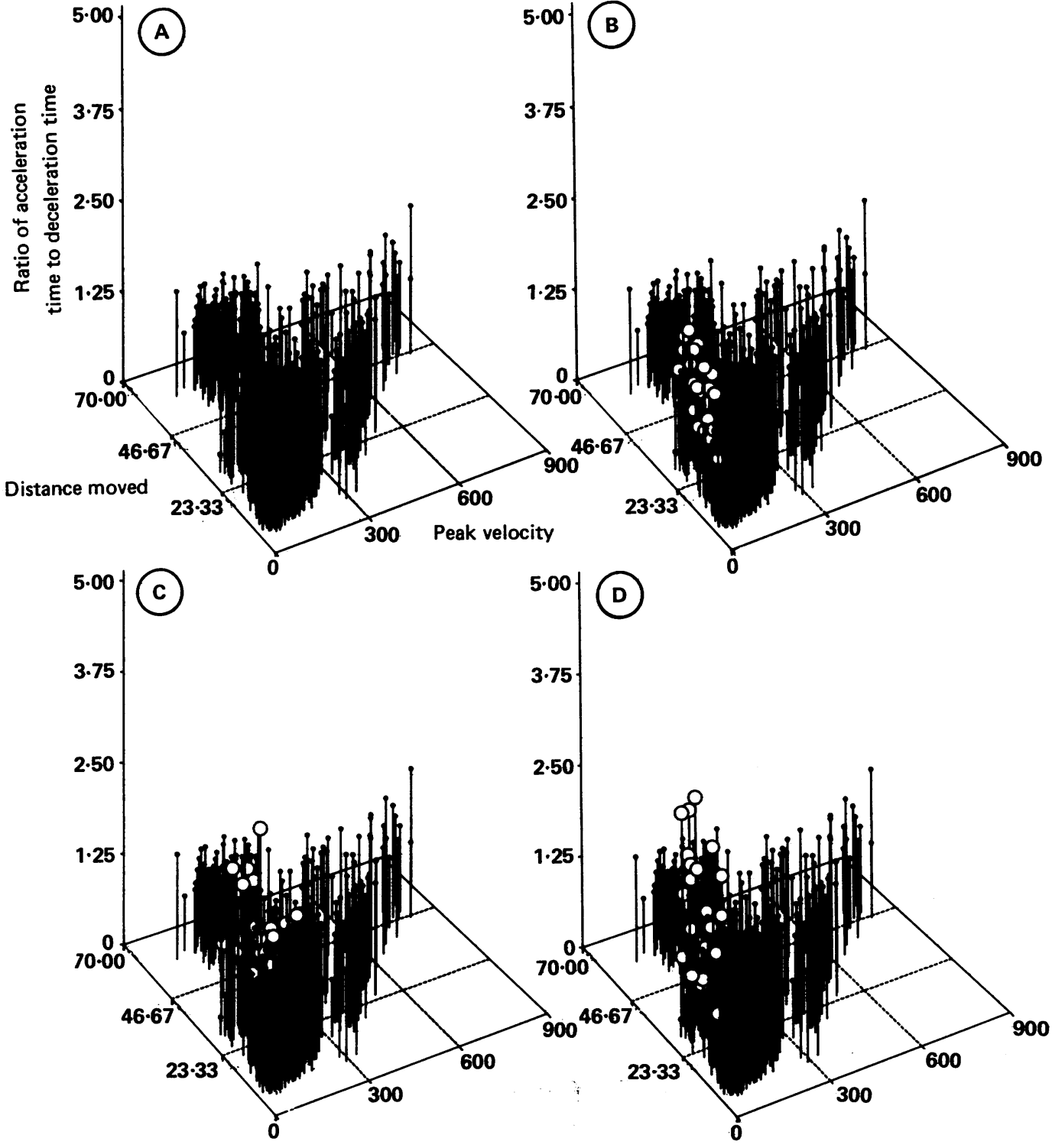

indicating a kinematic abnormality even when movement distance and peak velocity were considered simultaneously. The three patients $(4,7$, and 11) who had normal acceleration times were the same ones who had a normal duration of the first agonist burst.

We used a similar three-dimensional plot to study the ratio of acceleration time to deceleration time for individual movements as a function of the distance moved and the peak velocity

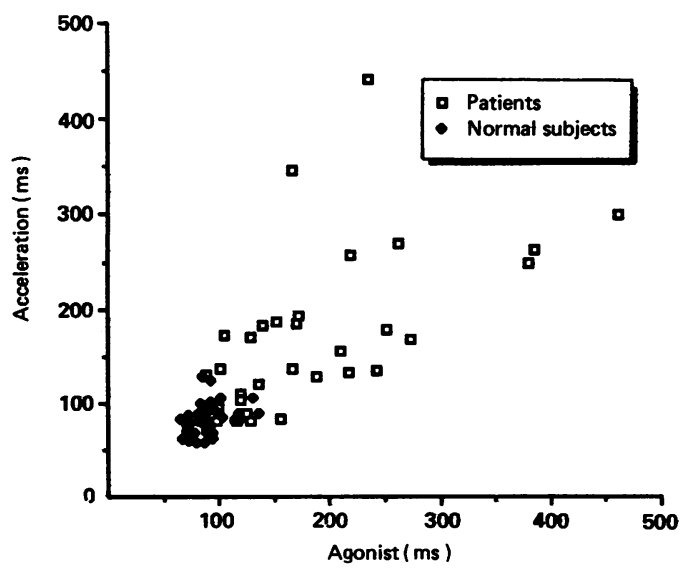

(fig 6). The normal surface was flat (with an approximate value of 1.0 ) for all fast movements and sloped downward with slower movements. An abnormality of the ratio was found for nine patients.

\section{Relationship of EMG to kinematic parameters} We studied the correlations in individual subjects between the first agonist burst duration and various kinematic parameters, including distance moved, peak velocity, movement time, acceleration time, deceleration time, and mismatch (the difference between the aimed distance and the actual distance moved). The best correlate to the first agonist burst duration was the acceleration time. The correlation ranged from 0.11 to 0.86 (mean, 0.53 ) for normal subjects and 0.06 to 0.75 (mean, 0.26 ) for patients. Using the mean values for pooled data on distance aimed for normal subjects and patients, ANOVA showed a highly significant relationship ( $p<0.001)$ between acceleration time and agonist duration (fig 7 ).

\section{Discussion}

Current theories of motor control suggest that movements are first planned, then executed, 
and finally corrected during the execution if the goal of the movement is not being achieved. There is evidence that the lateral part of the cerebellum is involved in the initial planning and that the intermediate part of the cerebellum is involved in the correction phase. Theoretically, there would be no time for correction if a movement was made quickly enough, and such a movement would be called ballistic. Simple monophasic movements made as rapidly as possible, at least in normal subjects, are often thought to be ballistic. Certainly, the triphasic EMG pattern that characterises these movements is generated centrally as part of the original motor plan, because the pattern is present even in the absence of peripheral feedback, as in deafferented patients. The details of the first agonist burst have provided some information on the planning of movement and the function of the lateral cerebellum.

Obtaining exact measurements of burst duration in individual movements is difficult, and the method has often been merely intuitive. By adopting stringent criteria, we attempted to make the method more objective. One difficulty in the measurements, which indicates an interesting feature of the physiology, is the cocontraction bursts, including the antagonist with the first agonist burst and the agonist with the first antagonist burst. The presence or absence of the co-contraction activity has no immediately apparent effect on the kinematics. The effect of the co-contraction may largely relate to stiffness of the joint during the movement. Although it was not specifically studied, we have the impression that co-contraction activity is lessened when the subject is relaxed.

This study confirms and extends the earlier finding ${ }^{10}$ that the duration of the first agonist burst is prolonged in patients with cerebellar deficits. Difficulty in measurements, including tonic patterns, indicates that the abnormality is even more severe than the measurements indicate. This feature is manifest for many of the patients even when slowness of movement and hypermetria are considered. The degree of the abnormality correlates with the extent of ataxia. The abnormality has been seen also with movements of the top joint of the thumb ${ }^{11}$ (Hallett et al, unpublished observations). An extensively studied primate model of patients with cerebellar deficits is reversible dysfunction of the dentate nucleus (or other deep nuclei) created with a cooling probe. ${ }^{12}$ The animals show movements that resemble those of patients, with long first agonist bursts in simple movements ${ }^{1314}$ or prolonged EMG bursts with alternating movements. ${ }^{15}$ Additionally, cooling the dentate nucleus produces prolongation of the phasic discharge of neurons in motor cortex that fire before movement. ${ }^{16}$

The most dramatic kinematic abnormality is the prolonged acceleration time. The abnormality holds even in relation to the deceleration time and in relation to slow movements made by normal subjects. The movement trajectory rises slowly to a peak velocity, followed by abrupt deceleration. An abnormally long acceleration time correlates with the degree of ataxia and with the duration of the first agonist burst. A similar kinematic abnormality is found in the primate model, ${ }^{14} 17$ indicating that movements made by animals with cerebellar lesions are not merely "inappropriate selection or triggering of an otherwise normal motor program." ${ }^{\prime 14}$ We would echo this view.

An abnormality of velocity in patients with cerebellar disease is in accord with studies of single-cell behaviour in cerebellum recorded from performing primates. In several different circumstances, cellular activity has correlated with the velocity of movement as the best kinematic variable. ${ }^{18-20}$

It seems reasonable to find that the primary EMG abnormality, prolonged duration of the first agonist burst, and the most dramatic kinematic abnormality, prolonged acceleration time, correlate with each other. The implication is that the limb is accelerated for approximately the same time as the agonist EMG is active. The error of producing a long acceleration time would seem the most fundamental problem of simple movements for patients with cerebellar deficits. Hypermetria should be a common resultant movement error unless there is compensatory reduction in the magnitude of the acceleration or compensatory increase in the magnitude of the deceleration. Acceleration is reduced in the patients, but this may be part of the problem. Deceleration magnitude may be increased, and this may be compensatory. Kinematic features are more easily measured than EMG parameters and may be preferred in future studies.

There is no clear explanation of the prolonged first agonist burst and the prolonged acceleration time. The kinematics indicates a reduction in the peak force exerted by the agonist muscle. In one respect, this is a paradoxical observation, since none of these patients was clinically weak as tested with tonic muscle contraction. This reduction in force was not due to the antagonist, since neither gross co-contraction nor inappropriately early activation of the antagonist was a notable feature. There are two possible reasons for the discrepancy in peak force and the prolongation of the first agonist burst and acceleration time. One of these may be that the primary abnormality is an inability to turn off the agonist muscle activity. We and others have previously speculated that the cerebellum, as an "inhibitory machine," has a role in terminating the first agonist burst properly. If the burst is obligatorily long, then to make movements of the correct distance patients must compensate by reducing the magnitude of the activity.

The other possible reason for the prolonged agonist burst is that the patients have difficulty in producing phasic muscle force. This explanation is consistent with the frequent observation that the beginning of the burst grows slowly rather than abruptly as in normal performance. In the most rapid voluntary contractions, spinal motor neurons reach discharge rates as high as $200 \mathrm{~Hz}$. Presumably, the motor units in cerebellar patients do not achieve such 
high rates. If the cerebellum contributes to the onset of a voluntary motor command, in cerebellar patients, the descending phasic motor output would be smaller than normal. This has been seen in monkeys trained to make self-terminated reaction time movements where cooling the dentate nucleus led to a decrease in peak velocity of movement. ${ }^{16}$ The decreased phasic descending command was reflected in a reduction in the phasic discharge of precentral cells before the onset of movement.

Prolonged duration of EMG bursts during rapid arm movements has been observed in other pathological conditions such as the upper motor neuron syndrome, ${ }^{2122}$ athetosis, ${ }^{23}$ Huntington's disease, ${ }^{24}$ and dystonia. ${ }^{25}$ The physiological dysfunction is not fully understood in any of these conditions, but may well be different from that occurring in cerebellar disturbance. For example, in the upper motor neuron syndrome, there is significant disturbance of the descending command with abnormalities of spatial and temporal recruitment of motor units, and in athetosis there is significant co-contraction of the antagonist muscle. Slowness of movement is not necessarily linked to prolongation of EMG bursts, however, since in Parkinson's disease the burst amplitude is low and the duration is normal. ${ }^{26} 27$

These studies were carried out in four laboratories: Institute of Psychiatry in London, Brigham and Women's Hospital in Boston, Department of Neurology in Rome, and NINDS in Bethesda. The work was started when MH was supported by a Moseley Travelling Fellowship (Harvard Medical School) and working in the Institute of Psychiatry in 1975. A majority of the data was collected in Boston when $\mathrm{MH}$ was Head of the Clinical Neurophysiology Laboratory, JM was a fellow in Clinical Neurophysiology Laboratory, JM was a fellow in Clinical
Neurophysiology, and AB was a fellow supported by CNR, Neurophysiology, and AB was a fellow supported by CNR,
NATO. Additional work was done in London when AB was a fellow there supported by the Medical Research Council. The fellow there supported by the Medical Research Council. The laboratory at the Brigham and Women's Hospital was supported by a biomedical research suppor

nstitutes of Health to the hospital.
We are grateful to the many people who participated in these studies by building equipment, writing computer programs, helping with experiments or making comments, including most importantly Richard Weinhaus, and B J Hessie who provided editorial expertise. We are particularly grateful to Vail Reese and Judy Fabrikant, who helped with the final data analysis.

1 Holmes G. The cerebellum of man. Brain 1939;62:1-30.

2 Kornhuber $\mathrm{HH}$. Motor functions of cerebellum and basal ganglia: The cerebellocortical saccadic (ballistic) click, the cerebellonuclear hold regulator, and the basal ganglia ramp (voluntary speed smooth movement) generator. Kybernetik 1971;8:157-62.
3 Eccles J. Cerebellar function in the control of movement. In: Rose FC, ed Physiological aspects of clinical neurology. Oxford: Blackwell, 1977:157-78.

4 Gilman S, Bloedel JR, Lechtenberg R. Disorders of the Cerebellum. Philadelphia: F A Davis, 1981.

5 Hallett M, Shahani BT, Young RR. EMG analysis of stereotyped voluntary movements in man. $J$ Neurol Neurosurg Psychiatry 1975;38:1154-62.

6 Freund H-J, Büdigen HJ. The relationship between speed and amplitude of the fastest voluntary contractions of human arm muscles. Exp Brain Res 1978;31:1-12.

7 Hallett M, Marsden CD. Ballistic flexion movements of the human thumb. J Physiol (Lond) 1979;294:33-50.

8 Berardelli A, Rothwell JC, Day BL, Kachi T, Marsden CD. Duration of the first agonist EMG burst in ballistic arm movements. Brain Res 1984;304:183-7.

9 Brown SH, Cooke JD. Initial agonist burst duration depends on movement amplitude. Exp Brain Res 1984;55:523-7.

10 Hallett M, Shahani BT, Young RR. EMG analysis of patients with cerebellar deficits. $j$ Neurol Neurosurg Psychiatry 1975;38:1163-9.

11 Marsden CD, Merton PA, Morton HB, Hallett M, Adam J, Rushton DN. Disorders of movement in cerebellar disease in man. In: Rose FC, ed. Physiological aspects of clinical in man. In: Rose FC, ed. Physiological aspect

12 Brooks VB. Cerebellar functions in motor control. Hum Neurobiol 1984;2:251-60

13 Meyer-Lohmann J, Conrad B, Matsunami K, Brooks VB. Effects of dentate cooling on precentral unit activity following torque pulse injections into elbow movements. Brain Res 1975;94:237-51.

14 Flament D, Hore J. Movement and electromyographic disorders associated with cerebellar dysmetria. $J$ Neurophysiol 1986;55:1221-33.

15 Conrad B, Brooks VB. Effects of dentate cooling on rapid alternating arm movements. J Neurophysiol 1974;37: 792-804.

16 Meyer-Lohmann J, Hore J, Brooks VB. Cerebellar participation in generation of prompt arm movements. Neurophysiol 1977;40:1038-50.

17 Brooks VB, Kozlovskaya IB, Atkin A, Horvath FE, Uno M Effects of cooling dentate nucleus on tracking-task performance in monkeys. J Neurophysiol 1973;36:974-95.

18 Robertson LT, Grimm RJ. Responses of primate denate neurons to different trajectories of the limb. Exp Brain Res 1975;23:447-62.

19 Thach WT. Correlation of neural discharge with pattern and force of muscular activity, joint position, and direction of intended next movement in motor cortex and cerebellum. $J$ Neurophysiol 1978;41:654-76.

20 Burton JE, Onoda N. Interpositus neuron discharge in relation to a voluntary movement. Brain Res 1977; relation to

21 Hallett $M$. Ballistic elbow flexion movements in patients with amyotrophic lateral sclerosis. J Neurol Neurosurg with amyotrophic latera

22 Fagioli S, Berardelli A, Hallett M, Accornero N, Manfredi $M$. The first agonist and antagonist burst in patients with upper motor neurone syndrome. Movement Disorders 1988;3:126-32.

23 Hallett $M$, Alvarez N. Attempted rapid elbow flexion movements in patients with athetosis. $J$ Neurol Neurosurg Psychiatry 1983;46:745-50.

24 Thompson PD, Berardelli A, Rothwell JC et al. The coexistence of bradykinesia and chorea in Huntington's disease and its implications for theories of basal ganglia control of movement. Brain 1988;111:223-44.

25 Van der Kamp W, Berardelli A, Rothwell JC, Thompson PD, Day BL, Marsden CD. Rapid elbow movements in PD, Day BL, Marsden CD. Rapid elbow movements in patients with torsion dy

26 Hallett $M$, Khoshbin S. A physiological mechanism of bradykinesia. Brain 1980;103:301-14.

27 Berardelli A, Dick JPR, Rothwell JC, Day BL, Marsden CD. Scaling of the size of the first agonist EMG burst during rapid wrist movements in patients with Parkinson's disease. J Neurol Neurosurg Psychiatry 1986; 49:1273-9. 